\title{
Induced Mutagenesis Enhances Lodging Resistance and Photosynthetic Efficiency of Kodomillet (Paspalum Scrobiculatum)
}

\author{
James Poornima Jency ${ }^{1}$, Ravikesavan Rajasekaran ${ }^{1, *(1)}$, Roshan Kumar Singh ${ }^{2}$, \\ Raveendran Muthurajan ${ }^{3}$, Jeyakumar Prabhakaran ${ }^{4}$, Muthamilarasan Mehanathan ${ }^{2}$, \\ Manoj Prasad ${ }^{2}$ and Jeeva Ganesan ${ }^{1}$ \\ 1 Department of Millets, Centre for Plant Breeding and Genetics, Tamil Nadu Agricultural University, \\ Coimbatore 641003, Coimbatore, India; poornimajames@gmail.com (J.P.J.); jeevagss@gmail.com (J.G.) \\ 2 National Institute of Plant Genome Research, Aruna Asaf Ali Marg, New Delhi 110067, Delhi, India; \\ sroshan@nipgr.ac.in (R.K.S.); muthamilarasan@nipgr.ac.in (M.M.); manoj_prasad@nipgr.ac.in (M.P.) \\ 3 Centre for Plant Molecular Biology and Biotechnology, Tamil Nadu Agricultural University, \\ Coimbatore 641003, Coimbatore, India; raveendrantnau@gmail.com \\ 4 Department of Crop Physiology, Tamil Nadu Agricultural University, Coimbatore 641003, Coimbatore, India; \\ jeyakumar@tnau.ac.in \\ * Correspondence: chithuragul@gmail.com; Tel.: +62-910422-2450507
}

Received: 26 December 2019; Accepted: 27 January 2020; Published: 4 February 2020

\begin{abstract}
The present research was focused in the development of photosynthetically efficient (PhE) and non-lodging mutants by utilizing ethyl methane sulphonate (EMS) and gamma radiation in the kodomillet variety $\mathrm{CO} 3$, prone to lodging. Striking variations in a number of anatomical characteristics of leaf anatomy for PhE and culm thickness for lodging resistance was recorded in $\mathrm{M}_{2}$ (second mutant) generation. The identified mutants were subjected to transcriptomic studies to understand their molecular basis. Expression profiling was undertaken for pyruvate phosphate dikinase (PPDK), Nicotinamide Adenine Dinucleotide Phosphate Hydrogen-(NADPH) and NADP-dependent malate dehydrogenase (NADP-MDH) in the mutants CO 3-100-7-12 (photosynthetically efficient) and in CO 3-200-13-4 (less efficient). For lodging trait, two mutants CO 3-100-18-22 (lodged) and CO 3-300-7-4 (non-lodged) were selected for expression profiling using genes GA2ox6 and Rht-B. The studies confirmed the expression of PPDK increased 30-fold, NADP-ME2 1-fold and NADP-MDH10 was also highly expressed in the mutant CO 3-100-7-12. These expression profiles suggest that kodomillet uses an NADP-malic enzyme subtype $C_{4}$ photosynthetic system. The expression of $R h t-B$ was significantly up regulated in $\mathrm{CO} 3-300-7-4$. The study highlights the differential expression patterns of the same gene in different lines at different time points of stress as well as non-stress conditions. This infers that the mutation has some effect on their expression; otherwise the expression levels will be unaltered. Enhancement in grain yield could be best achieved by developing a phenotype with high $\mathrm{PhE}$ and culm with thick sclerenchyma cells.
\end{abstract}

Keywords: induced mutation; lodging resistance; photosynthetic efficiency; transcriptomics

\section{Introduction}

India is rich in agro-biodiversity and a large number of crop species are being cultivated. The growing population to a great extent depend on two crops, rice and wheat, for sustenance. In this context, the potentials of indigenous crop plants including millets are being gradually revisited for their genetic constitution which is becoming increasingly relevant in the changing agricultural scenario. Climatic and edaphic opponents are the present challenges in agricultural production. As a consequence, any innate 
crop species with comparative advantages under these challenging environments need to be targeted [1]. One category that is expected to support the decline in agricultural production includes small millets that contribute for the food security in dry and marginal lands where the major cereal crops like rice and wheat are unsuccessful pertaining to yield.

The small millet group is represented by six crops, namely, finger millet, kodomillet, foxtail millet, little millet, prosomillet and barnyard millet. Among the six crops, kodomillet (Paspalum scrobiculatum L.) is indigenous to India [2]. Being a $C_{4}$ plant, it is gaining attention due to its suitability to changing agro-climatic conditions as most of the arable land (69\%) in India are arid and dry.

Lodging is a limitation in most of the small millet crops causing considerable losses in grain yield. Cultivating lodging-resistant plants is the most productive way to shrink losses due to lodging. Also, stem lodging disturbs the photosynthetic effectiveness of the canopy by affecting the grain filling which was reported in rice [3]. By reducing rice canopy photosynthesis, rice grain yield and quality was reduced by $60 \%-80 \%$ since these traits had negative associations with lodging. With a view to increasing the yield potential, identification of the superior sources, assessment of variability for the different morphological traits, increased photosynthetic efficiency and lodging resistance lines will add more value to the crop.

Nowadays, as opposed to the main cereals, there is an impetus to develop millets because of the predominant nutritional level. It is been said that kodomillet has more free radicals than other millets [4]. In addition, it provides low cost protein, minerals and vitamins in the form of healthy food [5].

The present investigation is an assessment of the extent of genetic variability induced for two traits viz., photosynthetic efficiency and lodging resistance, through physical (gamma rays) and chemical (ethyl methane sulphonate, EMS) mutagens and to isolate productive mutants in $\mathrm{M}_{2}$ ( mutant second) generation. The mutants of the desirable types for both the traits were identified and subjected to transcriptomic studies to understand their molecular basis. For future genetic and genomic studies the transcriptomal data provided in this crop will help improve the less studied, but nutritionally rich and sustainable crop.

\section{Materials and Methods}

\subsection{Plant Material}

The genetic variability was induced in Kodomillet variety $\mathrm{CO} 3$ using different treatments of physical mutagen (gamma rays) and chemical mutagen (EMS). The accessions were provided by the Department of Millets, Centre for Plant Breeding and Genetics, Tamil Nadu Agricultural University, Coimbatore.

\subsection{Methodology for Generating Mutant Population and Identifying the Desirable Mutants}

Mature and viable seeds (moisture $12.0 \%$ ) of the kodomillet variety CO 3 were irradiated at 100 , 200, 300 and 400 Gy with a radioisotope ${ }_{60} \mathrm{Co}$ (Cobalt-60) which served as a source at the gamma chamber installed at Bhabha atomic research centre, Kalpakkam. The percentage of moisture content was determined based on the difference between fresh weight and dry weight of the seeds following the International Seed Testing Association guideline [6]. About 500 seeds were packed in butter paper covers and placed in the gamma chamber at different time intervals for each dose based on the half-life of the source. Non-irradiated dry seeds were taken as control. For chemical treatments, presoaked $(8 \mathrm{~h})$ seeds were mutaginized with different doses of EMS, viz., $(0.2 \%),(0.3 \%),(0.4 \%)$ and $(0.5 \%)$ at a room temperature of $28 \pm 1{ }^{\circ} \mathrm{C}$. A sample of seeds soaked in distilled water for the respective duration was utilized as control. Initially, the doses for chemical and physical treatments were determined based on lethal dose $\left(\mathrm{LD}_{50}\right)$ values based on the probit analysis [7,8] from the germination and survival test [9]. 1000 seeds from each treatment were grown in the raised nursery beds established at the Department of Millets with respective controls. The spacing was maintained at $45 \mathrm{~cm}$ (between the rows) and $10 \mathrm{~cm}$ (between the seeds). A total set of 138 (58 gamma radiation and 80 EMS) self-pollinated fertile $\mathrm{M}_{1}$ plants were harvested individually and healthy seeds from each harvested plant were sown in plant 
progeny rows for growing $\mathrm{M}_{2}$ generation (Figure 1). A set of 102 mutants (43 gamma radiation and 59 EMS) selected in $\mathrm{M}_{2}$ generation were evaluated and validated.

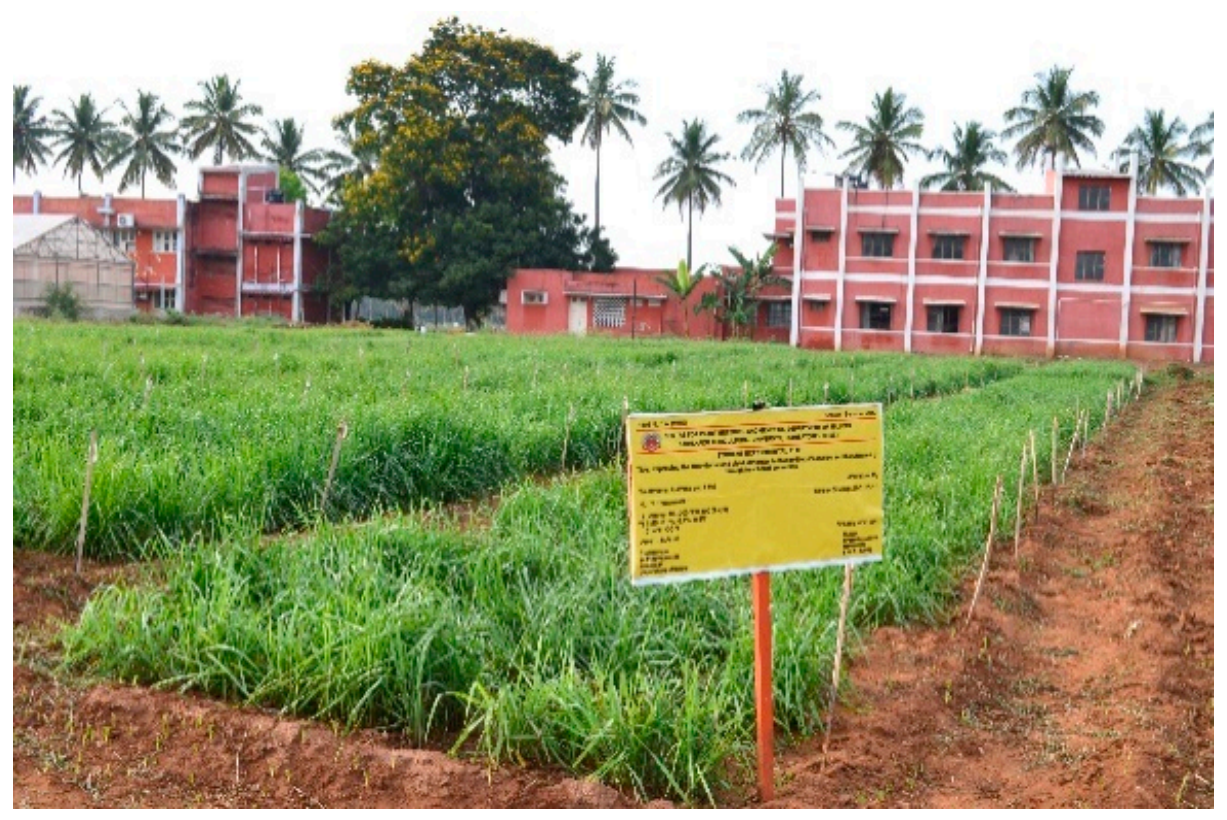

Figure 1. Field view of the $\mathrm{M}_{2}$ (mutant second) generation.

The mutagenized population was screened for the deviations in phenotypic characters in comparison with the control plants for two characters 1) photosynthetic efficiency (PhE), and 2) lodging resistance. For PhE, traits like flag leaf length $(\mathrm{cm})$, flag leaf breadth $(\mathrm{cm})$, chlorophyll index, measured using the soil plant analysis development (SPAD) meter (SPAD-502, Minolta Co., Osaka, Japan) and stomatal distribution calculated from epidermal impressions of mature, fully expanded leaf abaxial surface [10] were recorded. The stomata length and width were measured at 40× magnification to the nearest micrometer. Stomatal density was measured by counting the number of stomata per field of view at a magnification of $40 \times$. The following observations were made for lodging resistance, culm thickness (millimeter), culm strength by measuring the pushing resistance of the stem using a handy force-gauge meter, [11] (Figure 2). In microtome, cross sections of intermodal region from the unique mutants were studied for their difference in thickness (micrometres) of the culm and of the width in the sclerenchymatous cells. These quantitative phenotypic trait values were utilized for assessing the promising mutant line pertaining to $\mathrm{PhE}$ and lodging resistance which was further utilized for the transcriptome analysis.

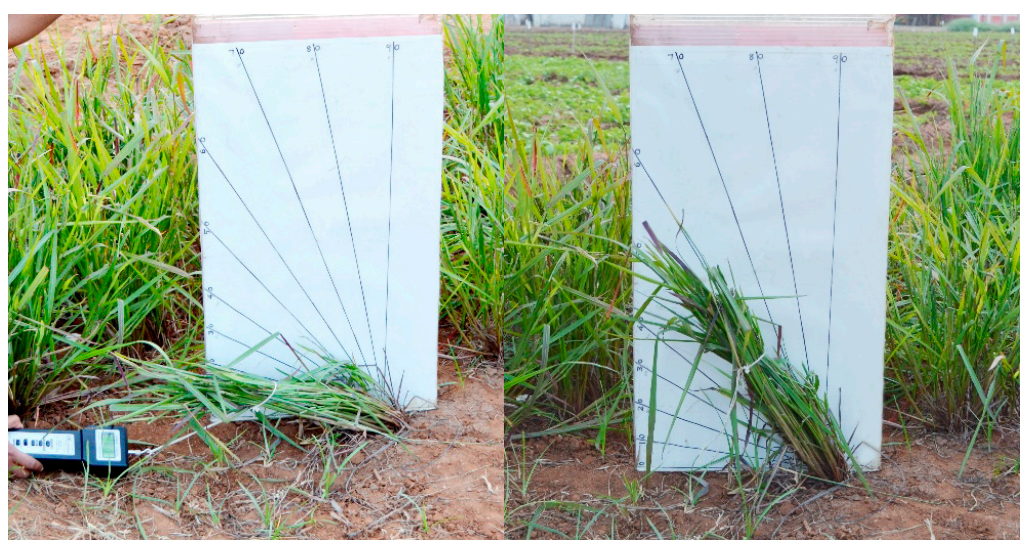

Figure 2. Push-pull gauge used to measure the culm strength in the mutant population. 


\subsection{Stress Treatment, RNA Isolation, $c D N A$ Synthesis and Quantitative RealTime-Polymerase Chain Reaction (qRT-PCR) Analysis}

The seeds of four extreme mutants (CO3-100-7-12-photosynthetically efficient; CO 3-200-13-4-less efficient; CO 3-300-7-4-non-lodged and CO 3-100-18-22-lodged) along with the wild type were grown in a plant growth chamber (PGC-6L; Percival Scientific Inc., Perry, USA) facility at the National Institute of Plant Genome Research, New Delhi, under the following conditions: $28 \pm 1{ }^{\circ} \mathrm{C}$ day/ $23 \pm 1{ }^{\circ} \mathrm{C}$ night $/ 70 \pm 5 \%$ relative humidity with a photoperiod of $14 \mathrm{~h}$ and a photosynthetic photon flux density of $500 \mu \mathrm{mol} \mathrm{m} \mathrm{m} \mathrm{s}^{-1}$. The plants were watered daily with one-third strength Hoagland's solution. For abiotic stress treatments, 21-day-old seedlings were exposed to $20 \%$ polyethylene glycol (PEG) 6000 (dehydration). Whole seedlings were collected at $0 \mathrm{~h}, 6 \mathrm{~h}$ and $12 \mathrm{~h}$ post-treatments. Zero-hour samples were used as controls. All the tissues were immediately frozen in liquid nitrogen after harvesting and stored at $-80^{\circ} \mathrm{C}$ until RNA isolation.

For all the samples i.e., control, photosynthetically efficient and non-efficient mutants, lodging resistant and lodged mutants, total RNA was prepared from the leaf samples using Trizol reagent [12] and treated with RNase-free DNase I (50 U/ $\mu \mathrm{L}$; Fermentas, Hanover, MD, USA). Quality and purity of isolated RNA was checked using a Nano Drop 1000 Spectrophotometer (Thermo Scientific, Wilmington, DE, USA) [OD260:OD280 $\mathrm{nm}$ absorption ratio (1.8-2.0)] and the integrity was ascertained by resolving on $1.5 \%$ agarose gel containing $18 \%$ formaldehyde. One microgram $(1 \mu \mathrm{g})$ of total RNA was reverse transcribed to first strand cDNA by anchored oligodT priming and random priming using a Thermo Scientific Verso cDNA synthesis kit following manufacturer's instructions. Quantitative realtime polymerase chain reaction (qRT-PCR) analysis was performed in StepOne ${ }^{\mathrm{TM}}$ Real-Time PCR Systems (Applied Biosystems, Foster City, USA) [13] using the primers mentioned in Table 1. The experiment was performed in three technical replicates for each biological duplicate. The amount of transcripts accumulated for each gene normalized to the internal control Act2 was analysed using the 2- $\Delta \Delta \mathrm{Ct}$ method [13]. The PCR efficiency was calculated as: Efficiency $=10(-1 /$ slope $)-1$ by the default software (Applied Biosystems, Foster City, USA).

Table 1. List of primers used for quantitative realtime-polymerase chain reaction (qRT-PCR) analysis.

\begin{tabular}{ccc}
\hline \multirow{2}{*}{ Primer Name } & Primer Sequence & Number of Bases \\
\hline \multirow{2}{*}{ SiPPDK2 } & F: GGTCGCAAAGCATGGCCTAA & 20 \\
\cline { 2 - 3 } SiNADP-ME2 & F: GAAGGCTCCCCACCATGTT & 19 \\
\cline { 2 - 3 } & R:GGCAAAGTCCTCAAACTGAATGA & 23 \\
\hline \multirow{2}{*}{ SiNADP-ME9 } & F: AGATTGGGCCCTTCTTATTGGT & 22 \\
\cline { 2 - 3 } SiNADP-MDH1 & R: GTAACGCAGCTCGCTCCATT & 20 \\
\cline { 2 - 3 } & R: GGCGTGACCACCCTAGATGTT & 21 \\
\hline \multirow{2}{*}{ SiNADP-MDH4 } & F: GCAGCAGTACGAGCGATTCA & 20 \\
\cline { 2 - 3 } SiNADP-MDH10 & R: GCCCCGCGTGTTGTTCT & 17 \\
\cline { 2 - 3 } & F: GTGGGAGAGGTTCTTGGACTTG & 22 \\
\hline \multirow{2}{*}{ SiNADP-MDH11 } & F: GGAATGGAGCGAGCTGACTT & 20 \\
\cline { 2 - 3 } & R: CCCCTGTTCCGCAAAAATC & 19 \\
\hline \multirow{2}{*}{ Rht-B } & F: ATGAAGCGSGAGTACCAGGA & 20 \\
\cline { 2 - 3 } R:TCTGCGCCACGTCCGCCATGTC & 22 \\
\hline \multirow{2}{*}{ RiGA2ox6 } & F: CGCCCTCATCGTCAA & 15 \\
\cline { 2 - 3 } & R: ACGCTCTTGTATCTGTTGTTG & 21 \\
\hline
\end{tabular}




\section{Results and Discussion}

\subsection{Determination of Lethal Dose $\left(L D_{50}\right)$ of Mutagens}

Induced mutation is essential to increase the rate of genetic variability as spontaneous mutation is at a slow rate that hampers the breeders to utilize them in the crop breeding programs. The major gain in induced mutation is that multiple trait mutants can be isolated. Before the beginning of the mutation-breeding program, information on the relative effectiveness of the mutagens is essential, [14] to determine the correct dose/concentration of the mutagens. Probit analysis was carried out using seed germination values for both the mutagens (gamma rays and EMS) to determine the $\mathrm{LD}_{50}$. The expected $\mathrm{LD}_{50}$ value for the seeds treated with gamma rays was $300 \mathrm{~Gy}$, in concordance with a previous study on radiation mutation $[15,16]$ in kodo millet and for EMS it was observed to be $34.83 \mathrm{mM}(0.4 \%)$. To comprehend, higher doses caused injury to the cell, which may be vital, and inhibited may cellular activities, eventually causing death of the cells. It had been noticed that, due to these chaos of the mutagens, seeds treated at high doses (500 Gy and 0.5\% EMS) did not germinate, or their seedlings could not survive beyond a few days [16]. A wide range of variations was noticed among the $\mathrm{M}_{2}$ generations for novel altered phenotypes in the traits viz., chlorophyll index, flag leaf length and breadth, stomatal number and length, culm thickness and culm strength.

\subsection{Identification of Photosynthetically Efficient Mutant Lines}

In order for plants to operate with efficiency, they need to balance the gaseous exchange from inside and outside the leaf to maximize carbon dioxide uptake for carbon assimilation and to attenuate water loss through transpiration. A total of seven mutants were selected for increased photosynthetic rate in the $\mathrm{M}_{2}$ generation (Table 2) out of which the mutant CO 3-100-7-12 had a flag leaf length of $28.47 \pm 0.50 \mathrm{~cm}$ which was comparatively less than the wild type, but there was an increase in the flag leaf breadth $(1.33 \pm 0.02 \mathrm{~cm})$ over the wild type $(1.17 \pm 0.01 \mathrm{~cm})$. It showed high chlorophyll index (47.97 \pm 0.91$)$ which possessed $79 \pm 1.46$ stomatas per unit leaf area accompanied by an increased stomatal length $(10.27 \pm 0.17 \mu \mathrm{m})$ which was higher than the wild type. Stomatal number and length is related to specific stomatal conductance responsible for increased photosynthesis leading to higher yield. There were significant differences in number of stomata and length of stomatal apparatus among the selected mutants (Figure 3).

Table 2. Mutants screened for photosynthetic efficiency in $\mathrm{M}_{2}$ generation.

\begin{tabular}{ccccccc}
\hline S.No. & Mutants & $\begin{array}{c}\text { Stomatal } \\
\text { Number }\end{array}$ & $\begin{array}{c}\text { Stomatal } \\
\text { Length }(\boldsymbol{\mu m})\end{array}$ & $\begin{array}{c}\text { Chlorophyll } \\
\text { Index }\end{array}$ & $\begin{array}{c}\text { Flag Leaf } \\
\text { Length }(\mathbf{c m})\end{array}$ & $\begin{array}{c}\text { Flag Leaf } \\
\text { Breadth }(\mathbf{c m})\end{array}$ \\
\hline 1 & CO 3-100-1-5 & $45.00 \pm 1.46$ & $9.03 \pm 0.17$ & $38.97 \pm 0.91$ & $22.77 \pm 0.50$ & $1.30 \pm 0.02$ \\
\hline 2 & $\begin{array}{c}\text { CO 3-100-7-12 } \\
(\text { high efficient) }\end{array}$ & $79.00 \pm 1.46$ & $10.27 \pm 0.17$ & $47.97 \pm 0.91$ & $28.47 \pm 0.50$ & $1.33 \pm 0.02$ \\
\hline 3 & CO 3-200-1-3 & $58.00 \pm 1.46$ & $7.99 \pm 0.12$ & $41.37 \pm 0.70$ & $18.10 \pm 0.52$ & $1.20 \pm 0.01$ \\
\hline 4 & CO 3-200-4-1 & $71.00 \pm 1.46$ & $9.16 \pm 0.12$ & $35.20 \pm 0.70$ & $19.57 \pm 0.52$ & $1.17 \pm 0.01$ \\
\hline 5 & CO 3-200-14-1 & $56.00 \pm 1.46$ & $8.85 \pm 0.12$ & $37.00 \pm 0.70$ & $20.27 \pm 0.52$ & $1.30 \pm 0.01$ \\
\hline 6 & CO3-40.25-12-4 & $58.00 \pm 1.33$ & $9.90 \pm 0.13$ & $37.57 \pm 0.60$ & $32.33 \pm 0.62$ & $1.30 \pm 0.03$ \\
\hline 7 & CO 3-40.25-30-2 & $61.00 \pm 1.33$ & $9.46 \pm 0.13$ & $41.97 \pm 0.60$ & $29.10 \pm 0.62$ & $1.57 \pm 0.03$ \\
\hline & CO 3 200-13-4 & $27.00 \pm 1.46$ & $9.18 \pm 0.12$ & $34.10 \pm 0.70$ & $28.17 \pm 0.52$ & $1.00 \pm 0.01$ \\
\hline
\end{tabular}

Stomata are the "doorkeepers" that regulate the volume of $\mathrm{CO}_{2}$ infiltrating the intercellular air spaces of the leaf for photosynthesis. Earlier studies suggest that the increase in stomatal 
density translates to an increase in stomatal conductance and 30\% greater photosynthetic rate under high light conditions in Arabidopsis [17]. Increased stomatal density enhanced leaf photosynthetic capacity in Arabidopsis [18]. The mutant CO 3-200-13-4 had the least stomatal count $(27 \pm 1.46)$ per unit leaf area. Therefore, stomatal density may be a target trait for plant engineering to improve photosynthetic capacity.

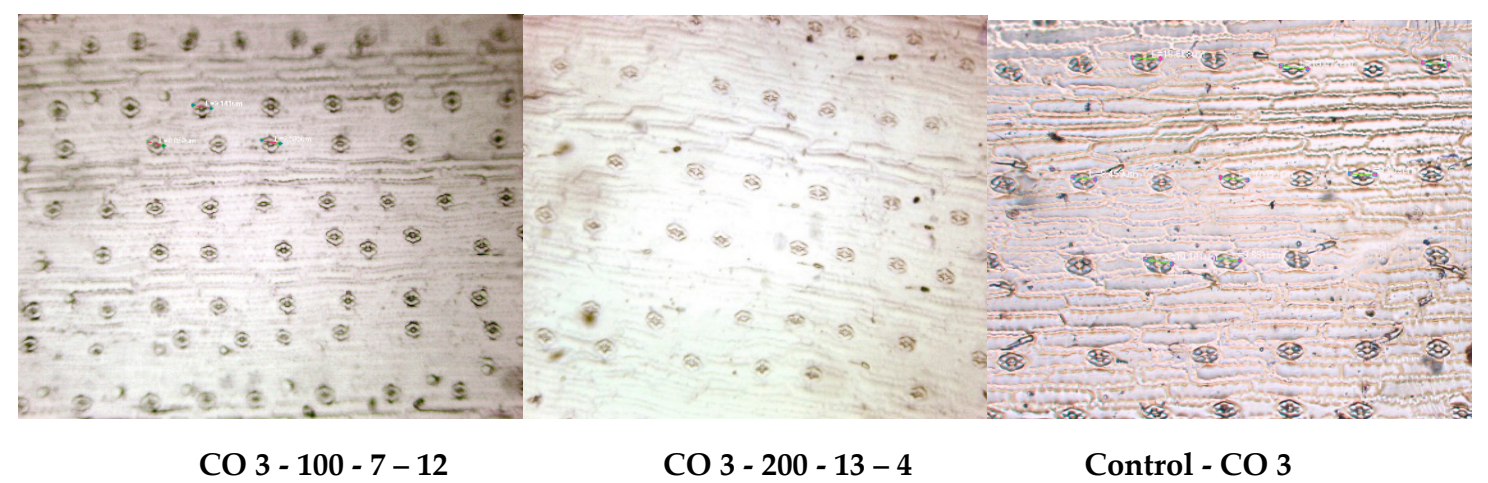

Figure 3. Stomatal distribution on the leaf epidermis of the identified extreme mutants along with control for photosynthetic efficient trait.

\subsection{Identification of Non-Lodging Mutant Lines}

Lodging is usually referred to as a condition in which the stem of a crop bends at or near the surface of the ground, which could lead to the collapse of the canopy. Nine mutants showed superior lodging resistance in the $\mathrm{M}_{2}$ generation until the time of harvest. The mutant CO 3-300-7-4 exhibited the thickest culm diameter of $4 \pm 0.24 \mathrm{~mm}$ over the wild type $(2.53 \pm 0.12 \mathrm{~mm})$. The bending of the crop stem at the ground surface was measured using the handy force gauge meter, and the strength of the highly resistant mutant (CO 3-300-7-4) was $39.73 \pm 1.75$ newtons, while the culm of the wild type exerted a strength of $24.53 \pm 1.50$ newtons (Table 3 ). The association of pulling force with other characters indicated that the mutant lines with high culm strength were taller than the wild and possessed thick culm, more productive tillers, and increased yield [19]. Not much work has been published on kodomillet relating to culm strength and lodging resistance. Nevertheless, rice has been used as a model crop for understanding the mechanical properties of culm in which the phenotypical traits such as pushing resistance $[20,21]$ and stem diameter [22] were involved in evoking culm strength and for lodging resistance.

Table 3. Mutants screened for lodging trait in $\mathrm{M}_{2}$ generation.

\begin{tabular}{cccc}
\hline S.No. & Mutants & Culm Thickness $(\mathbf{m m})$ & Culm Strength (newtons) \\
\hline 1 & CO 3-100-7-3 & $3.30 \pm 0.07$ & $34.73 \pm 1.62$ \\
\hline 2 & CO 3-100-10-5 & $3.47 \pm 0.07$ & $22.08 \pm 1.62$ \\
\hline 3 & CO 3-200-16-3 & $3.53 \pm 0.05$ & $29.73 \pm 1.80$ \\
\hline 4 & CO 3-200-17-2 & $3.53 \pm 0.05$ & $24.18 \pm 1.80$ \\
\hline 5 & CO 3-200-19-4 & $3.90 \pm 0.05$ & $39.63 \pm 1.80$ \\
\hline 6 & CO 3-300-2-5 & $2.90 \pm 0.24$ & $43.65 \pm 1.75$ \\
\hline 7 & CO 3-300-7-4 (highly stable) & $4.00 \pm 0.24$ & $39.73 \pm 1.75$ \\
\hline 8 & CO 3-40.25-13-2 & $3.13 \pm 0.05$ & $30.27 \pm 1.63$ \\
\hline 9 & CO 3-40.25-18-5 & $3.10 \pm 0.05$ & $34.49 \pm 1.63$ \\
\hline
\end{tabular}


Based on culm thickness and culm strength, nine mutants (Table 3) were selected for non- lodging trait. The cross sectional anatomy for the identified mutants was analyzed using scanning electron microscopy (SEM, Figure 4).

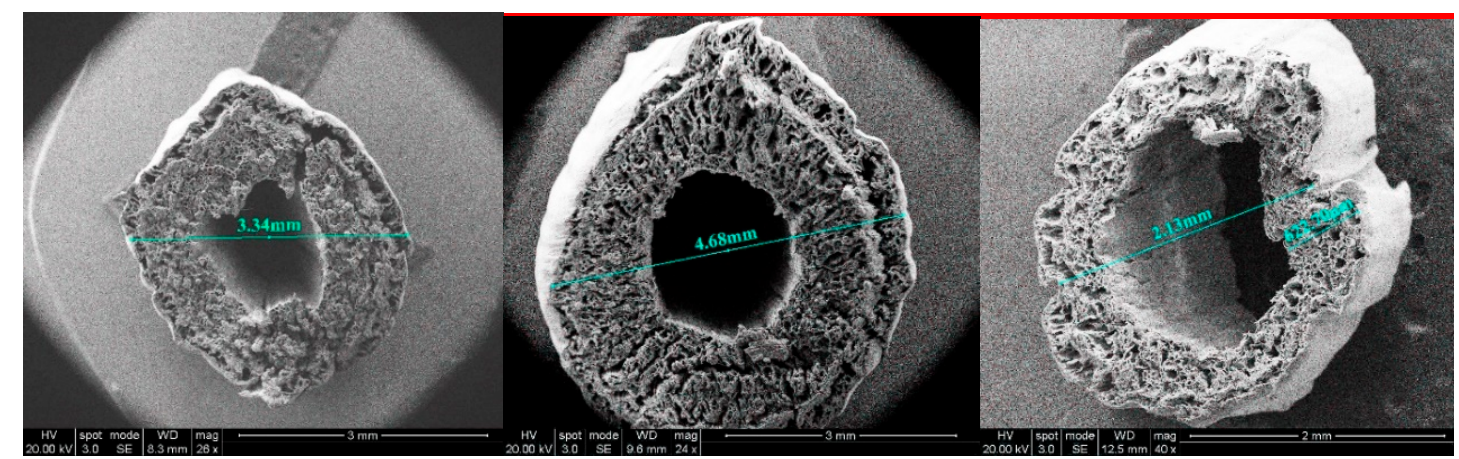

Control - CO 3

$$
\text { CO } 3-300-7-4
$$

CO 3 - 100 - 18 - 22.

Figure 4. Section of the internodal regions in the wild ( $\mathrm{CO} 3)$ and extreme mutants studied through scanning electron microscopy (SEM).

Thickness of sclerenchymatous cell (TSC) showed distinct variations that provided rigidity and culm strength. TSC of the mutants ranged from $8.61 \mu \mathrm{m}$ to $16.01 \mu \mathrm{m}$, whereas the thickness of the wild type (CO 3) was $11.09 \mu \mathrm{m}$. The mutant CO 3-300-7-4 had the thickest TSC $(16.01 \mu \mathrm{m})$. The mutant CO 3-100-18-22 showed the thinnest TSC $(8.61 \mu \mathrm{m})$ (Figure 5). The information that culm strength is positively correlated with the thickness of sclerenchyma cell walls explained the better lodging resistance in barley [23].

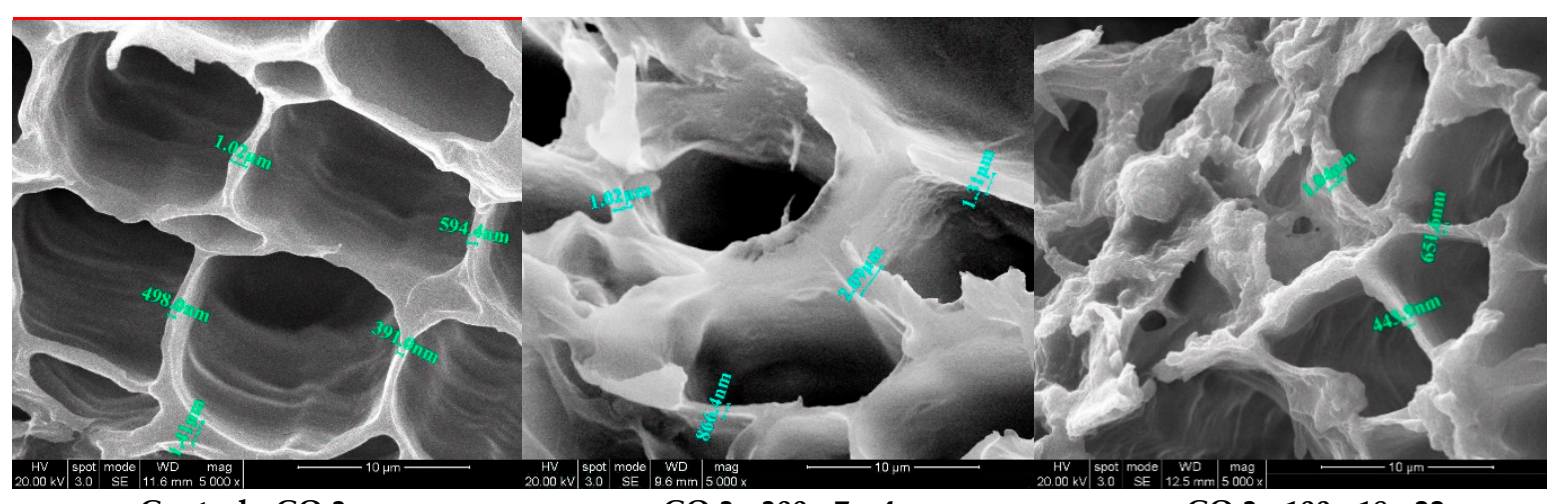

Control - $\mathrm{CO} 3$

CO $3-300-7-4$

CO 3 - $100-18-22$

Figure 5. Transverse section of the sclerenchyma cells in the wild (CO 3) and in the extreme mutants.

Reduction in the mechanical strength of a plant may reflect alterations in cell wall structure, composition and fiber length. Therefore, cell-wall shape examined under SEM for the selected mutants revealed that the mutant's (CO 3-300-7-4) sclerenchyma cell wall was thickened (Figure 6), in striking contrast with the wild-type sclerenchyma's cell wall. The sclerenchyma of mutant CO 3-100-18-22 had the thinnest cell walls. Not much published evidence is available to substantiate this phenomenon in this crop. 


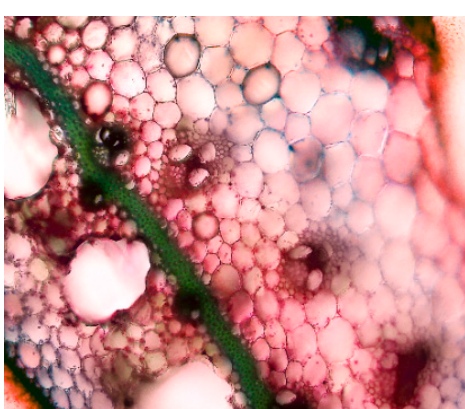

Control - $\mathrm{CO} 3$

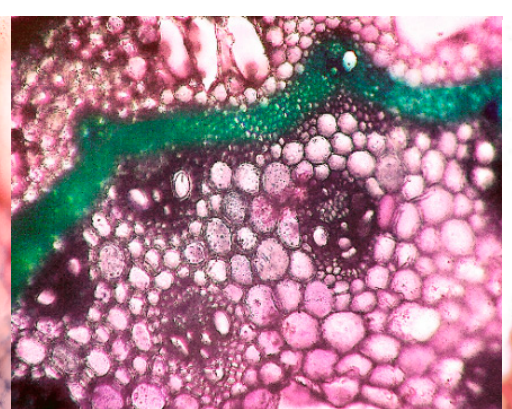

CO $3-300-7-4$

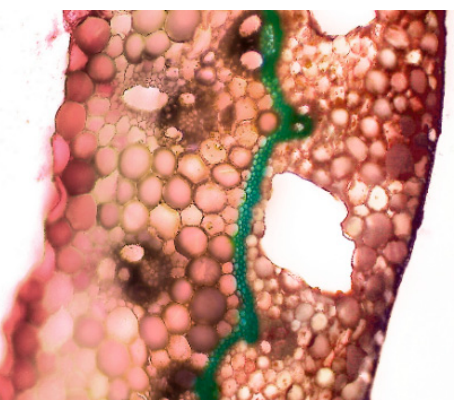

CO $3-100-18-22$

Figure 6. Cross-section of the extreme mutants depicting the thickness of the sclerenchyma cell along with the wild type (CO 3$)$.

\subsection{Molecular Characterization of Mutants through Transcriptomics}

Characterization of the extreme mutants identified for non-lodging and photosynthetically efficient lines were done through transcriptomics. Comparative transcript profiling has always been a key to analyzing the dynamics of gene expression in two contrasting mutants. This provides preliminary evidence of transcript abundance of a given gene in two mutants that might be differentially regulated. Differential regulation of the same gene in two contrasting varieties of the same crop has been reported in several species. For example, a small heat shock protein-encoding gene of foxtail millet, sHSP27, has shown a 30-fold upregulation in the leaves of tolerant cultivar (cv. IC-4) at the early stages of heat stress as compared to susceptible cultivar (cv. IC-41) [24]. This demonstrates that the same gene could be differentially expressed in different mutants at a given time, which could be due to the difference in the regulation of gene expression at transcript-level. Keeping this in mind, the expression profiles of seven genes for photosynthetic efficiency and two candidate genes for lodging were chosen for expression profiling in the following mutant lines.
$\mathrm{CO} 3$
Control
CO 3-100-7-12 : Mutant line with better photosynthetic efficiency
CO 3-200-13-4 : Mutant line with low photosynthetic efficiency
CO 3-100-18-22 : Lodged mutant type
CO 3-300-7-4 : Non-lodged mutant type

\subsubsection{Expression Profiling of $\mathrm{C}_{4}$ Photosynthetic Genes}

Millets belong to the $\mathrm{C}_{4}$ photosynthetic group of Poaceae where carbon assimilation is performed through three key steps [25]. First is the conversion of $\mathrm{CO}_{2}$ to $\mathrm{HCO}^{-}$by carbonic anhydrase $(\mathrm{CaH})$ which is then fixed to oxaloacetate, $\mathrm{a}_{4}$ acid, by phosphoenol pyruvate carboxylase (PEPC) in the mesophyll cell. This $\mathrm{C}_{4}$ acid intermediate is converted to malate by Nicotinamide adenine dinucleotide phosphate-dependent malate dehydrogenase (NADP-MDH). Secondly, the malate diffuses to bundle sheath where an NADP-malic enzyme (NADP-ME) performs decarboxylation to release $\mathrm{CO}_{2}$ and pyruvate. The refixation of $\mathrm{CO}_{2}$ is attained by ribulose-1, 5-bisphosphate carboxylase (Rubisco) in the Calvin cycle. Thirdly, the pyruvate, orthophosphate dikinase (PPDK) converts pyruvate to phosphoenolpyruvate (PEP) in the mesophyll [26]. Thus, in contrast to $\mathrm{C}_{3}$ cycle, photosynthetic efficiency of $\mathrm{C}_{4}$ crops is higher ( $\sim 50$ folds) which confers several climate resilient adaptabilities including survival in high temperatures, high light intensities, radiations and drought conditions [27,28].

Recently, the complete $\mathrm{C}_{4}$ enzyme repertoire of sequenced Poaceae genomes with emphasis on foxtail millet has been identified [29] (Figure 7). 


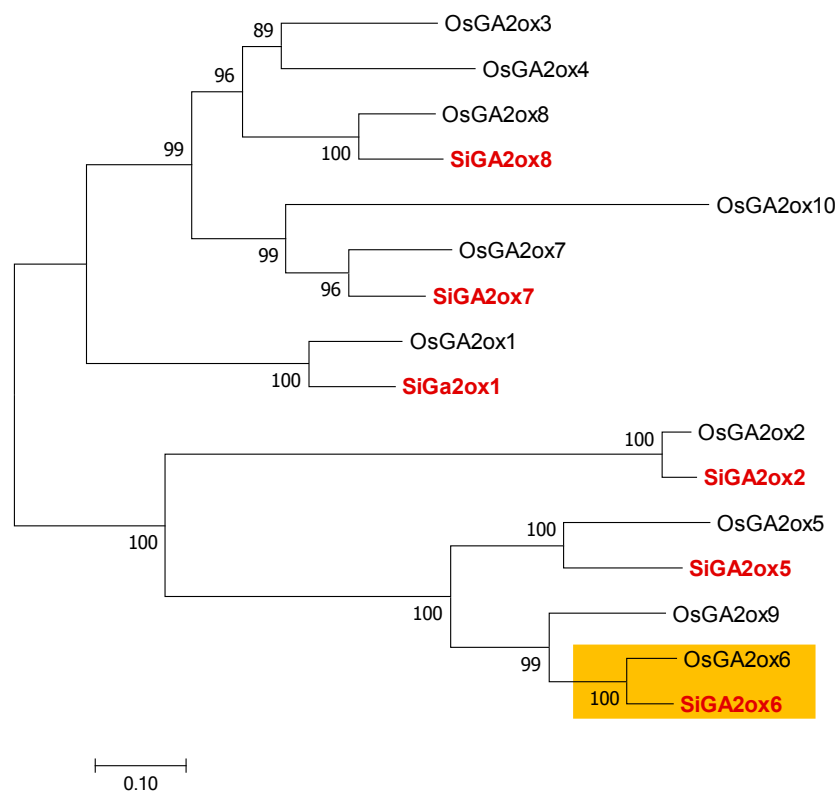

Figure 7. Evolutionary relationships of OsGA2ox and SiGA2ox. The candidate gene chosen for expression analysis is shown within the box.

\subsubsection{Pyruvate, Orthophosphate Dikinase (PPDK)}

The expression of PPDK in Control CO 3, CO 3-100-7-12 and CO 3-200-13-4 at 0 hr. was unaltered; however, a significant upregulation was observed in $\mathrm{CO} 3$ and $\mathrm{CO} 3-100-7-12$ at $6 \mathrm{~h}$ post-dehydration treatment (more than 10 -fold). At $12 \mathrm{~h}$, the expression was down regulated in $\mathrm{CO} 3$ and upregulated in $\mathrm{CO}$ 3-100-7-12 and CO 3-200-13-4. Approximately 30-fold higher expression of PPDK was observed at $12 \mathrm{~h}$ post-treatment in CO 3-100-7-12 (Figure 8) which suggests that the expression may confer higher enzyme activity to ensure the effective functioning of $C_{4}$ photosynthesis. Similar observations were reported [27] where the expression of PPDK kept increasing in a bioenergy feedstock grass Miscanthus $\times$ giganteus during chilling stress. However, a decline in expression was observed in maize [30].'Over expression of maize PPDK in Arabidopsis showed a 4-fold upregulation in the expression, and the photosynthetic rates of transgenic plants had also increased [28].



Figure 8. Relative expression profile of pyruvate, orthophosphate dikinase (PPDK) gene analyzed using qRT-PCR under dehydration stress for $0 \mathrm{~h}$ (control), $6 \mathrm{~h}$ (early) and $2 \mathrm{~h}$ (late) in 21 day-old seedlings of CO 3, CO 3-100-7-12, and CO 3-200-13-4. The relative expression ratio of each gene was calculated relative to its expression in control sample $(0 \mathrm{~h})$. SiAct2 was used as an internal control to normalize the data. Error bars representing standard deviation were calculated based on three technical replicates for each biological duplicate. 


\subsubsection{Nicotinamide Adenine Dinucleotide Phosphate Hydrogen. (NADPH)}

$\mathrm{C}_{4}$ species are divided into subtypes, named for the primary decarboxylating enzyme that is localized to the bundle sheath. Maize, sorghum, and sugarcane use an NADP-dependent malic enzyme (NADP-ME subtype), whereas switch grass and teff (Eragrostis tef) use an NAD-malic enzyme (NAD-ME subtype) to generate a $\mathrm{CO}_{2}$ pump in the bundle sheath cells. Most $\mathrm{C}_{4}$ lineages are of the NADP-ME subtype [31].

In the present study, at $6 \mathrm{hr}$ post-stress, NADP-ME2 was down regulated in CO 3-100-7-12 whereas NADP-ME9 did not show any difference as compared to control. At $12 \mathrm{~h}$, NADP-ME2 was up regulated ( 1-fold) in the better performing line, CO 3-100-7-12, whereas an incremental down regulation was observed in NADP-ME9. Both CO 3 and CO 3-200-13-4 showed increased levels of NADP-ME2, where CO 3-200-13-4 exhibited a 5-fold over expression in the $12 \mathrm{~h}$ sample. Similar elevated levels were observed for NADP-ME9; however, the relative expression levels were similar at both $6 \mathrm{~h}$ and $12 \mathrm{~h}$ samples in CO 3 and CO 3-200-13-4 (Figure 9). These expression profiles suggest that kodomillet uses an NADP-malic enzyme subtype $\mathrm{C}_{4}$ photosynthetic system to fix carbon and, therefore, is a potentially powerful model system for dissecting $\mathrm{C}_{4}$ photosynthesis.
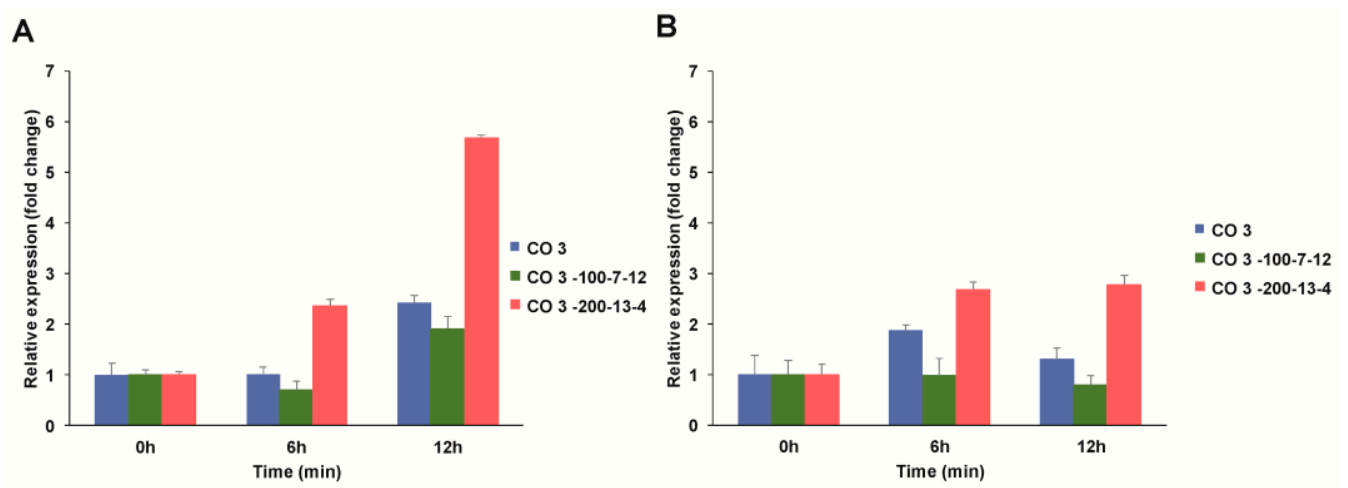

Figure 9. Relative expression profile of (A) Nicotinamide Adenine Dinucleotide Phosphate-Malic Enzyme2 (NADP-ME2) and (B) Nicotinamide Adenine Dinucleotide Phosphate-Malic Enzyme9 (NADP-ME9) genes analyzed using qRT-PCR under dehydration stress for $0 \mathrm{~h}$ (control), $6 \mathrm{~h}$ (early) and $2 \mathrm{~h}$ (late) in 21-day-old seedlings of CO 3, CO 3-100-7-12, and CO 3-200-13-4.

\subsubsection{Nicotinamide Adenine Dinucleotide Phosphate -Malate dehydrogenase (NADP-MDH)}

In case of NADP-MDH1, there was no much difference in the expression levels across the lines, but a 2- to 3-fold up regulation was observed in $\mathrm{CO} 3$ at 6 and $12 \mathrm{~h}$ samples. The expression was unaltered in CO 3-100-7-12, whereas a significant down regulation was observed in CO 3-200-13-4 at the $12 \mathrm{~h}$ sample. NADP-MDH4 exhibited a similar expression profile in $\mathrm{CO} 3$, where an interesting observation of $\sim 4$-fold up regulation was noted in $6 \mathrm{~h}$ and $12 \mathrm{~h}$ samples. At $6 \mathrm{~h}$ post-stress, the level of NADP-MDH4 was almost similar in CO 3-100-7-12 and CO 3-200-13-4, but at 12 h, CO 3-200-13-4 showed a 1-fold up regulation. By contrast, NADP-MDH10 was highly expressed in CO 3-100-7-12 and CO 3-200-13-4 during stress as compared to control, and in case of non-stress condition $(0 \mathrm{~h})$, elevated expression was observed in CO 3-200-13-4 followed by CO 3-100-7-12 as compared to CO 3 . These results indicate regulation of this enzyme is sensitive to dehydration in mutated plants. The gene NADP-MDH11 showed an initial up regulation at $6 \mathrm{~h}$ post-stress in CO 3-100-7-12 but down regulated at $12 \mathrm{~h}$. In contrast, the transcript levels were increased with time in $\mathrm{CO} 3$ and $\mathrm{CO} 3-200-13-4$ (Figure 10) Similar differential expression of MDH genes was reported in wheat [32], Arabidopsis [33], maize [34], apple [35] and cotton [36]. 

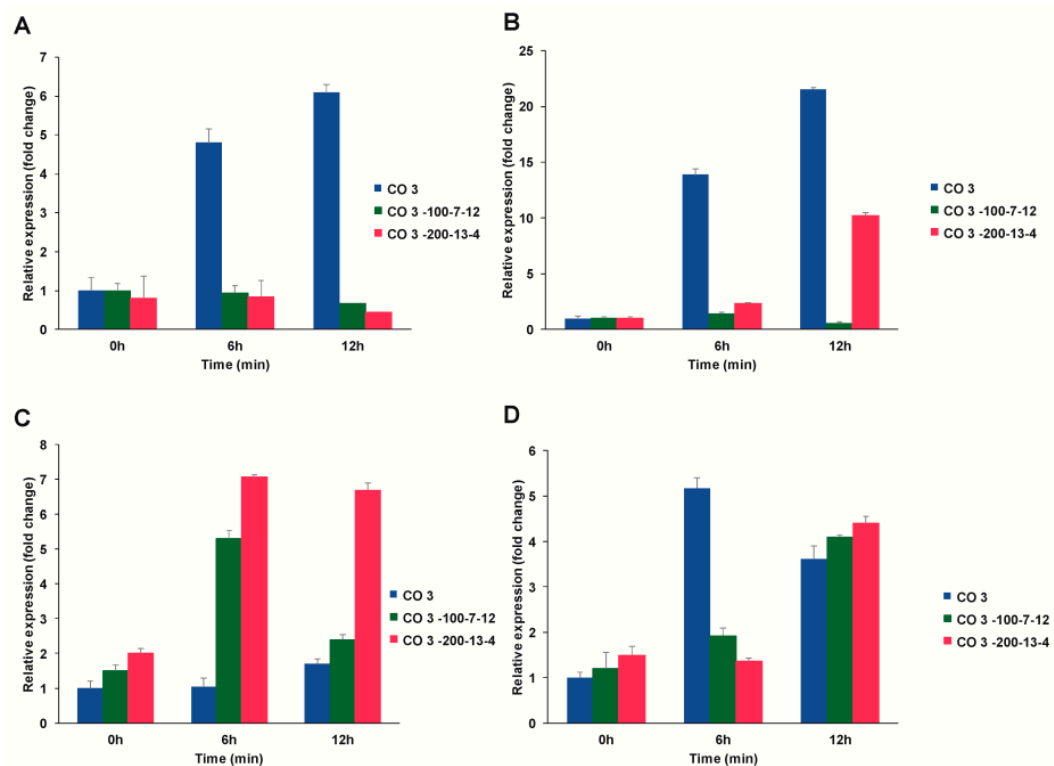

Figure 10. Relative expression profile of (A) NADP-MDH1, (B) NADP-MDH4, (C) NADP-MDH10, and (D) NADP-MDH11 genes analyzed using qRT-PCR under dehydration stress for $0 \mathrm{~h}$ (control), $6 \mathrm{~h}$ (early) and $2 \mathrm{~h}$ (late) in 21-day-old seedlings of CO 3, CO 3-100-7-12, and CO 3-200-13-4.

Attempts have been made to overexpress maize NAPD-ME in rice through a transgenic approach, which showed a 20- to 70-fold increase in enzyme activity; however, the transgenic lines had aberrant chloroplast [30]. Over expressing sorghum NADP-ME in rice showed 1- to 7-fold increase in the enzyme activity in transgenic lines with null-positive effect on photosynthesis [37]. All the over expression studies have demonstrated enhanced photo inhibition of photosynthesis due to an increase in the level of NADPH inside the chloroplast by the action of the $\mathrm{C}_{4}$-NADP-ME enzyme. These suggest that the cellular circuitry associated with NADP-ME is very complex in $\mathrm{C}_{4}$ plants and thus over expressing a single gene from $C_{4}$ to $C_{3}$ will show detrimental effects in the transgenic lines.

\subsubsection{Expression Profiling of Lodging-Related Genes}

Two genes were reported to be responsible for lodging resistance in rice and wheat, and interestingly, both were related to the plant growth hormone, gibberellic acid (GA). GAs control a variety of growth and developmental processes during the entire life cycle of plants. Several loss-of-function mutants in GA biosynthesis showed typical GA-deficient phenotypes, such as dwarfism, small dark green leaves, prolonged germination dormancy, inhibited root growth, defective flowering, reduced seed production, and male sterility [38]. A major catabolic pathway for GAs is initiated by a $2 \beta$-hydroxylation reaction catalyzed by GA2 oxidases (GA2ox). In rice, 10 different classes of GA2ox were identified that were named GA2ox1 to GA2ox10, and in the present study, the GA2ox orthologs of foxtail millet were first identified. However, foxtail millet possesses only seven GA2ox genes where the orthologs of GA2ox4, GA2ox9 and GA2ox10 were absent. A phylogenetic tree constructed to derive the evolutionary relationships between rice and foxtail millet $G A 20 x$ proteins showed that two distinct classes of these proteins exist in both the crops [38]. The proteins GA2ox2, GA2ox5, GA2ox9 (ortholog absent in foxtail millet) and GA2ox6 formed a separate clade, and as shown by [39], these proteins contain the three unique and conserved motifs. At $12 \mathrm{~h}$ post-dehydration treatment, the expression of GA20x6 was significantly reduced in the mutant $\mathrm{CO} 3-100-18-22$, whereas an incremental decrease in gene expression was noticed in CO 3-300-7-4 (Figure 11). This could be due to the effect of mutation on the regulatory regions of the GA2ox6 or other gene(s) that could have a negative effect on GA2ox6 expression at the late-stage of dehydration stress. 


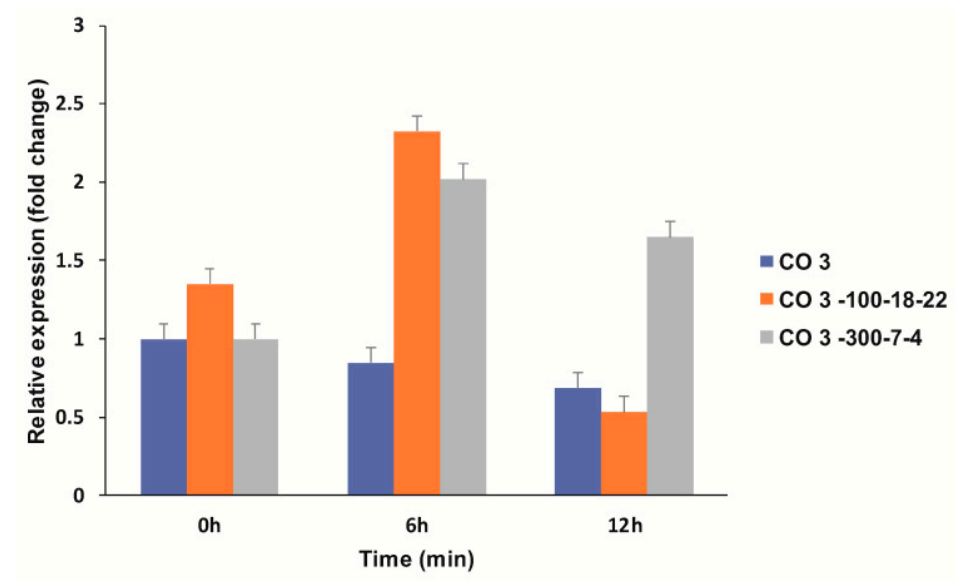

Figure 11. Relative expression profile of GA2ox6 gene analyzed using qRT-PCR under dehydration stress for $0 \mathrm{~h}$ (control), $6 \mathrm{~h}$ (early) and $2 \mathrm{~h}$ (late) in 21-day-old seedlings of CO 3, CO 3-100-18-22, and CO 3-300-7-4. The relative expression ratio of each gene was calculated relative to its expression in control sample $(0 \mathrm{~h})$. SiAct2 was used as an internal control to normalize the data. Error bars representing standard deviation were calculated based on three technical replicates for each biological duplicate.

The transcript abundance of the Rht-B gene in all the three lines (Control CO 3, CO 3-100-18-22, CO 3-300-7-4) suggests interesting evidence of GA-regulated stress responsive machinery that might operate in these lines and also, the mutation would have occurred in such a way as to impede the average expression of $R h t-B$ in CO 3-100-18-22 (Figure 12). In wheat, the mutant lines of $R h t-B 1 b$ and $R h t-D 1 b$ were suggested to confer dwarfism by producing more active forms of growth repressors [40].

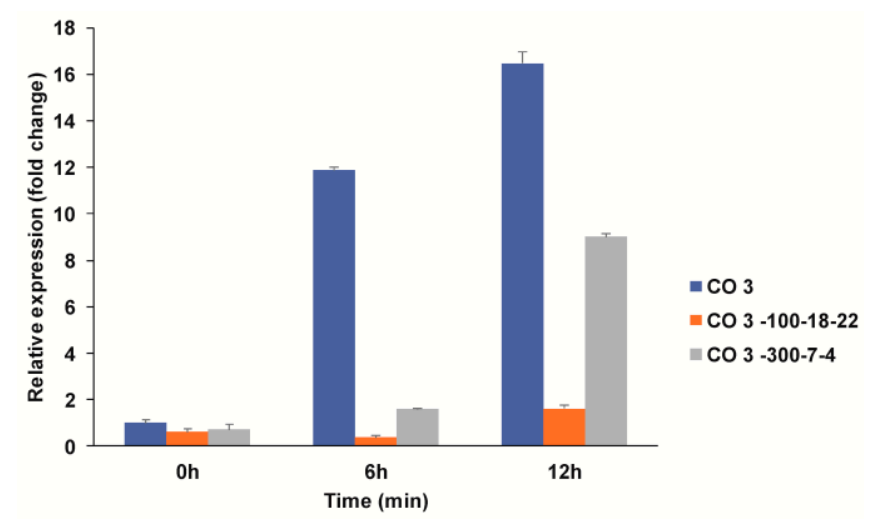

Figure 12. Relative expression profile of $R h t-B$ gene analyzed using qRT-PCR under dehydration stress for $0 \mathrm{~h}$ (control), $6 \mathrm{~h}$ (early) and $2 \mathrm{~h}$ (late) in 21-day-old seedlings of CO 3, CO 3-100-18-22, and CO 3-300-7-4.

\section{Conclusions}

The outcome of this study have shown striking variations for $\mathrm{PhE}$ and lodging resistance in a number of anatomical characteristics of flag leaf anatomy and culm thickness. The study highlights differential expression patterns of the same gene in different lines at different time points of stress as well as non-stress conditions. This infers that the mutation has some effect on their expression; otherwise the expression levels will be unaltered. Mutation in regulatory elements of each gene might have altered the motifs for recognition and binding of transcription factors, and this could have led to a differed transcriptional regulation of gene expression. Cloning and sequencing of the genes as well as their promoter regions can provide a clue about the variations that have been inserted through mutagenesis. However, the present data is very preliminary for drawing a solid conclusion, and further functional characterization is required to delineate the precise role of each gene in stress 
response and the impact of the mutation on the functioning of that particular gene. This also suggests that an improvement in grain yield could be best attained by a developing a phenotype with high $\mathrm{PhE}$ and culm with thick sclerenchyma cells.

Author Contributions: Conceptualization, project administration R.R.; supervision R.M.; J.P.J., R.K.S. and J.G. performed the experiments. J.P.J. analyzed the data and wrote the manuscript. M.M.; M.P. data curation, validation, resources and supervision; J.P. formal analysis. All authors have read and agreed to the published version of the manuscript.

Funding: This research was funded by UGC: Maulana Azad National Fellowship for Minority Students, F1-17.1/2016-17/MANF-2015-17-TAM-55427.

Acknowledgments: The authors profoundly acknowledge the Department of Millets, Tamil Nadu Agricultural University, Lab members of 103, NIPGR and the scientists at BARC, Kalpakam for the support rendered.

Conflicts of Interest: The authors declare no conflict of interest.

\section{References}

1. Padulosi, S.; Mal, B.; Ravi, S.B.; Gowda, J.; Gowda, K.T.K.; Shanthakumar, G.; Yenagi, N.; Dutta, N. Food security and climate change: Role of plant genetic resources of minor millets. Ind. J. Plant Genet. Res. 2009, 22, 1-16.

2. De Wet, J.M.J.; Prasada Rao, K.E.; Mengesha, M.H.; Brink, D.E. Diversity in kodo millet, Paspalum scrobiculatum. Econ. Bot. 1983, 37, 159-163. [CrossRef]

3. Weng, F.; Zhang, W.; Wu, X.; Xu, X.; Ding, Y.; Li, G.; Liu, Z.; Wang, S. Impact of low-temperature, over cast and rainy weather during the reproductive growth stage on lodging resistance of rice. Sci. Rep. 2017, 7, 46596. [CrossRef]

4. Hegde, P.S.; Chandra, T.S. ESR spectroscopic study reveals higher free radical quenching potential in kodo millet (Paspalum scrobiculatum) compared to other millets. Food Chem. 2005, 92, 177-182. [CrossRef]

5. Yadava, H.S.; Jain, A.K. Advances in kodo millet research. Directorate of Information and Publications of Agriculture. Indian Counc. Agric. Res. 2006.

6. ISTA. International rules for seed testing. Seed Sci. Technol. 1985, 13, 299-355.

7. Finney, D.J. Probit Analysis, 10th ed.; Cambridge University Press: Cambridge, UK, 1971.

8. Finney, D.J. Statistical Method in Biological Assay; Charles Griffin \& Co.: London, UK, 1978.

9. PoornimaJency, J.; Ravikesavan, R.; Sumathi, P.; Raveendran, M. Effect of chemical mutagen on germination percentage and seedling parameters in Kodomillet variety CO 3. Int. J. Chem. Std. 2017, 5, 166-169.

10. Sampson, J. A method of replicating dry or moist surfaces for examination by light microscopy. Nature 1961, 191, 932. [CrossRef]

11. Kashiwagi, T.; Ishimaru, K. Identification and functional analysis of a locus for improvement of lodging resistance in rice. Plant Physiol. 2004, 134, 676-683. [CrossRef]

12. Longeman, J.; Schell, J.; Willmitzer, L. Improved method for the isolation of RNA from plant tissues. Anal. Biochem. 1987, 163, 16-20. [CrossRef]

13. Kumar, K.; Muthamilarasan, M.; Manoj, P. Reference genes for quantitative real-time PCR analysis in the model plant foxtail millet (Setariaitalica L.) subjected to abiotic stress conditions. Plant Cell Tiss. Organ. Cult. 2013, 115, 13-22. [CrossRef]

14. Smith, H.H. Comparative genetic effects of different physical mutagens in higher plants. In Induced Mutations and Plant Breeding Improvement; IAEA: Vienna, Austria, 1972; pp. 75-93.

15. PoornimaJency, J.; Ravikesavan, R.; Sumathi, P.; Raveendran, M. Determination of lethal dose and effect of physical mutagen on germination percentage and seedling parameters in kodomillet variety CO 3. Electron. J. Plant Breed. 2016, 7, 1122-1126.

16. Subramanian, A.; Nirmalakumari, A.; Veerabadhiran, P. Mutagenic Efficiency and Effectiveness in Kodomillet (Paspalum scrobiculatum L.). Madras Agric. J. 2011, 98, 1-3.

17. Schluter, U.; Muschak, M.; Berger, D.; Altmann, T. Photosynthetic performance of an Arabidopsis mutant with elevated stomatal density (sdd1-1) under different light regimes. J. Exp. Bot. 2003, 54, 867-874. [CrossRef]

18. Tanaka, Y.; Sugano1, S.S.; Shimada, T.; Nishimura, I.H. Enhancement of leaf photosynthetic capacity through increased stomatal density in Arabidopsis. New Phytol. 2013, 198, 757-764. [CrossRef] 
19. Sreeja, R.; Subramanian, A.; Nirmalakumari, A.; Kannanbapu, J.R. Selection criteria for culm strength in Kodo millet (Paspalum scrobiculatum L.) to suit mechanical harvesting. Electron. J. Plant Breed. 2014, 5, 459-466.

20. Terashima, K.; Akita, S.; Sakai, N. Eco-physiological characteristics related with lodging tolerance of rice in direct sowing cultivation. Jpn. J. Crop Sci. 1992, 61, 380-387. [CrossRef]

21. Won, J.G.; Hirahara, Y.; Yoshida, T.; Imabayashi, S. Selection of rice lines using SPGP seedling method for direct seeding. Plant Prod. Sci. 1998, 1, 280-288. [CrossRef]

22. Zuber, U.; Winzeler, H.; Messmer, M.M.; Keller, B.; Schmid, J.E.; Stamp, P. Morphological traits associated with lodging resistance of spring wheat (Triticumaestivum L.). J. Agron. Crop Sci. 1999, 182, 17-24. [CrossRef]

23. Cenci, C.A.; Grando, S.; Ceccarelli, S. Culm anatomy in barley (Hordeum vulgare). Can. J. Bot. 1984, 62, 2023-2027. [CrossRef]

24. Roshan, K.S.; Jaishankar, J.; Muthamilarasan, M.; Shweta, S.; Dangi, A.; Manoj, P. Proteins in $C_{4}$ model, foxtail millet identifies potential candidates for crop improvement under abiotic stress. Sci. Rep. 2016, 6, 3264.

25. Pinto, H.; Sharwood, R.E.; Tissue, D.T.; Ghannoum, O. Photosynthesis of C3, C3-C4, and C4 grasses at glacial CO2. J. Exp. Bot. 2014, 65, 3669-3681. [CrossRef] [PubMed]

26. Furbank, R.T.; Chitty, J.A.; Jenkins, C.L.D.; Taylor, W.C.; Trevanion, J.S.; Caemmerer, S.V.; Ashton, A.R. Genetic manipulation of key photosynthetic enzymes in the $\mathrm{C}_{4}$ plant Flaveria bidentis. Aust. J. Plant. Physiol. 1997, 24, 477-485. [CrossRef]

27. Wang, D.A.R.P.; Stephen, J.; Moose, P.; Long, P.S. Cool C ${ }_{4}$ Photosynthesis: Pyruvate Pi Dikinase Expression and Activity Corresponds to the Exceptional Cold Tolerance of Carbon Assimilation in Miscanthus $\times$ giganteus. Plant Physiol. 2008, 148, 557-567. [CrossRef] [PubMed]

28. Wang, Y.M.; Xu, W.G.; Hu, L.; Zhang, L.; Li, Y.; Du, X.H. Expression of Maize Gene Encoding C4-Pyruvate Orthophosphate Dikinase(PPDK) and C4-Phosphoenolpyruvate Carboxylase (PEPC) in Transgenic Arabidopsis. Plant Mol. Biol. Rep. 2012, 30, 1367. [CrossRef]

29. Muthamilarasan, M.; Roshan, K.S.; Singh, N.K.; Prasad, M. C 4 photosynthetic enzymes of foxtail millet. Sci. Reps. 2018.

30. Takeuchi, Y.; Akagi, H.; Kamasawa, N.; Osumi, M.; Honda, H. Aberrant chloroplasts in transgenic rice plants expressing a high level of maize NADP-dependent malic enzyme. Planta 2000, 211, 265-274. [CrossRef]

31. Christin, P.A.; Salamin, N.; Kellogg, E.A.; Vicentini, A.; Besnard, G. Integrating phylogeny into studies of $\mathrm{C}_{4}$ variation in the grasses. Plant Physiol. 2009, 149, 82-87. [CrossRef]

32. Ding, Y.; Ma, Q.H. Characterization of a cytosolic malate dehydrogenase cDNA which encodes an isozyme toward oxaloacetate reduction in wheat. Biochimie 2004, 86, 509-518. [CrossRef]

33. Beeler, S.; Liu, H.C.; Stadler, M.; Schreier, T.; Eicke, S.; Lue, W.L.; Truernit, E.S.; Zeeman, S.C.; Chen, J.; Kotting, O. Plastidial NAD-Dependent Malate Dehydrogenase is Critical for Embryo Development and Heterotrophic Metabolism in Arabidopsis. Plant Physiol. 2014, 164, 1175-1190. [CrossRef]

34. Menckhoff, L.; Ehret, N.M.; Buck, F.; Vuleti, M.; Luthje, S. Plasma membrane-associated malate dehydrogenase of maize (Zea mays L.) roots: Native versus recombinant protein. J. Prot. 2013, 80, 66-77. [CrossRef] [PubMed]

35. Yao, J.; Ma, H.; Zhang, P.; Ren, L.; Yang, X.; Yao, G.; Zhang, P.; Zhou, M. Inheritance of stem strength and its correlations with culm morphological traits in wheat (Triticum aestivum L.). Can. J. Plant Sci. 2011, 91, 1065-1070. [CrossRef]

36. Wang, Z.A.; Li, Q.; Ge, X.Y.; Yang, C.L.; Luo, X.L.; Zhang, A.H.; Xiao, J.L.; Tian, Y.C.; Xia, G.X.; Chen, X.Y.; et al. The mitochondrial malate dehydrogenase 1 gene GhmMDH1 is involved in plant and root growth under phosphorus deficiency deficiency conditions in cotton. Sci. Rep. 2015, 5, 10343. [CrossRef] [PubMed]

37. Wei, C.; Song, Z.J.; Fang, Z.; Hu, W.U.N. Photosynthetic Features of Transgenic Rice Expressing Sorghum $\mathrm{C}_{4}$ Type NADP-ME. Acta Bot. Sinica 2004, 46, 873-882.

38. Lo, S.F.; Yang, S.Y.; Chen, K.T.; Hsing, Y.I.; Zeevaart, J.A.; Chen, L.J.; Yu, S.M. A Novel Class of Gibberellin 2-Oxidases Control Semi dwarfism, Tillering, and Root Development in Rice. Plant Cell 2008, 20, 2603-2618. [CrossRef] 
39. Lee, D.J.; Zeevaart, A.D.J. Molecular Cloning of GA 2-Oxidase3 from Spinach and Its Ectopic Expression in Nicotiana sylvestris. Plant Physiol. 2005, 138, 243-254. [CrossRef]

40. Pearce, S.; Saville, R.; Vaughan, S.P.; Chandler, P.M.; Wilhelm, E.P.; Sparks, C.A.; Kaff, N.A.; Korolev, A.; Boulton, M.I.; Phillips, A.L.; et al. Molecular Characterization of Rht-1 Dwarfing Genes in Hexaploid Wheat. Plant Physiol. 2011, 157, 1820-1831. [CrossRef] 